\title{
Pathophysiology of Leukocyte-Mediated Tissue Injury
}

\author{
Peter A. Ward, Gerd O. Till, and Jeffrey S. Warren
}

$\mathbf{C}^{\mathrm{o}}$ ONSIDERABLE new insights have been obtained regarding mechanisms of leukocyte-mediated tissue injury. Since endothelial cell injury often occurs during the acute inflammatory response, much work has been done to define in vitro mechanisms involving the killing of endothelial cells by activated neutrophils. $\Lambda \mathrm{t}$ the same time, the use of in vivo models of acute lung injury has allowed definition of events that can be linked to the development of acute vascular injury by products of activated phagocytic cells. We will briefly review recent studies that affect both topics.

\section{IN VITRO MECHANISMS OF ENDOTHELIAL CELL INJURY}

The development of in vitro culture methods during the past two decades has permitted a detailed analysis of pathways leading to the injury of vascular endothelial cells by activated neutrophils. Pulmonary vascular endothelial cells of bovine, ovine, and rat origin have been studied, in addition to cells derived from human umbilical vein endothelial cells (HUVECs). Although there have been some sporadic reports using human endothelial cells from other vascular beds, most work with human cells has been carried out using HUVECs. Our own studies have involved the use of rat pulmonary artery endothelial cells (RPAECs) to be able to make comparisons between the in vitro behavior of these cells with their fatc in vivo during acute inflammatory injury. It must be acknowledged that there are differences between endothelial cells related to species variations and that within a given species there may be considerable differences between the behavior of microvascular

From the Department of Pathology, The University of Michigan Medical School, Ann Arbor, MI.

Received February 28, 1991; accepted March 4, 1991.

Supported in part by NIH grants HL-31963, HL-07517, CA-26731, GM-29507, and GM-39397.

Address reprint requests to Peter $A$. Ward, MD, Department of Pathology, The University of Michigan Medical School, M5240 Medical Science I, Box 0602, 1301 Catherine Rd, Ann Arbor, MI 48109-0602

Copyright $\odot 1991$ by W.B. Saunders Company

0883-9441/91/0602-0008\$05.00/0 endothelial cells compared with aortic endothelial cells. These issues have not been carefully resolved because of the inherent difficulties in obtaining and maintaining endothelial cell culture lines that are of very limited passage in culture.

In the case of RPAECs, there is emerging evidence that defines the mechanisms by which activated neutrophils bring about damage. "Adhesive interactions" between neutrophils and RPAECs are important in bringing about the most efficient contact between these different cell types and facilitating the injury of endothelial cells by toxic products of activated neutrophils. Although only studied in a limited manner, adhesion-promoting molecules on the neutrophil include the $\beta 2$-integrin molecule (CD18), while on the endothelial cell, an important adhesion-promoting molecule is endothelial leukocyte adhesion molecule-1 (ELAM-1), which is reactive with a member of the selectin family of lectin-epidermal growth factor-complement regulatory protein cell adhesion molecules (LEC-CAMs) molecules on the neutrophil. Other LEC-CAMs include GMP140 and MEL-14 $\mu$, although whether these are important in neutrophil cytotoxic interactions with endothelial cells is not currently known. ${ }^{1}$ ELAM-1 binds with a carbohydrate moiety recently defined on the neutrophils, namely, sialyl-Le ${ }^{x}, 3$ The roles of CD18 on the neutrophil and of ELAM-1 on the endothelial cell infer that at least two distinct and independent binding interactions are linked to the cytotoxic outcome.

Another important, recently recognized finding is that endothelial cells exposed to cytokines such as tumor necrosis factor- $\alpha$ or interleukin- $1 \beta$ demonstrate upregulation of ELAM-1 and, accordingly, greatly increase adherence interactions between neutrophils and endothelial cells.' A correlate of this is that in such cases, endothelial cells that have been preexposed to either of the two cytokines demonstrate greatly increased susceptibility to killing by activated neutrophils. ${ }^{4}$

The production of toxic oxygen products by phorbol ester-stimulated neutrophils is a key 
feature to the cytotoxic effects on the endothelial cells. Although activated neutrophils generate both superoxide anion $\left(\mathrm{O}_{2}{ }^{-}\right)$and hydrogen peroxide $\left(\mathrm{H}_{2} \mathrm{O}_{2}\right)$, only the latter seems central to killing of endothelial cells since catalase, but not superoxide dismutase (which converts $\mathrm{O}_{2}^{-}$ to $\mathrm{H}_{2} \mathrm{O}_{2}$ ), is protective against neutrophilmediated killing of endothelial cells. ${ }^{5}$ It also appears that myeloperoxidase-induced conversion of $\mathrm{H}_{2} \mathrm{O}_{2}$ to hypochlorous acid $(\mathrm{HOCl})$ is not required for the in vitro killing of endothelial cells by activated neutrophils since chemical inactivation of myeloperoxidase does not reduce the cytotoxic effects of activated neutrophils. ${ }^{5} \mathrm{HOCl}$ may, however, play an important role in the injury of the vasculature by neutrophils, since their metalloproteinases (collagenase and gelatinase) can be directly activated by contact with $\mathrm{HOCl}$ (reviewed in ref 6).

$\mathrm{H}_{2} \mathrm{O}_{2}$ interactions with cndothelial cells result in an abrupt fall in intracellular levels of adenosine triphosphate (ATP). Within 20 minutes, these levels drop to less than $20 \%$ of the normal range. ${ }^{7}$ This fall is due to both reduced synthesis of ATP due to inactivation of glyceraldehyde-3phosphate dehydrogenase ${ }^{8}$ and to a breakdown of ATP into adenosind diphosphate, adenosine monophosphate, and adenosine, and the subsequent hydrolysis of adenosine (by the action of adenosine deaminase) to produce inosine, hypoxanthine, and xanthine.? The generation of the last two metabolites is important for the reasons described below.

Interaction of RPAECs with activated neutrophils results in an increase in intracellular xanthine oxidase.' This enzyme is known to be linked to the presence of its precursor enzyme, xanthinc dehydrogenase, which can be converted to xanthine oxidase by a reversible oxidative change or by an irreversible change that may be related to limited proteolysis of xanthine dehydrogenase. ${ }^{10}$ The "converting factor" from the neutrophil appears not to be a product of oxygen but, rather, seems to be due to elastase, a potent enzyme secreted from cytoplasmic granules of the neutrophil. ${ }^{11}$ The increase in xanthine oxidase within the endothelial cell as well as the appearance of its substrates in cells exposed to $\mathrm{H}_{2} \mathrm{O}_{2}$ sets the stage for the intracellular generation of $\mathrm{O}_{2}^{-}$. At present, it can be argued that observations dealing with rat endo- thelial cell may not be extrapolatable to HUVECs, since the latter do not contain measurable xanthine oxidase. On the other hand, subjecting HUVECs to anoxic conditions followed by reoxygenation has been reported to result in the appearance of xanthine oxidase activity, based on immunohistochemical and biochemical analyses. ${ }^{12}$ Recently, it also has been shown that venous outflow in the extremities of humans subjected to ischemia-reperfusion events results in the appearance of effluent plasma of xanthine oxidase. ${ }^{13}$ Thus, xanthine oxidase may exist in human endothelial cells in a cryptic or unexpressed form. It seems undeniably clear that damage to or killing of endothelial cells is the ultimate result of the formation of the highly reactive hydroxyl radical (HO-), whose most relevant target in the endothelial cell is not clear. HO is generated by one of two known pathways:

1. The iron-catalyzed Haber-Weiss reaction:

$$
\begin{aligned}
& \mathrm{O}_{2}^{-}+\mathrm{Fe}^{3+} \rightarrow \mathrm{O}_{2}+\mathrm{Fe}^{2+} \\
& \mathrm{Fe}^{2+}+\mathrm{H}_{2} \mathrm{O}_{2} \rightarrow \mathrm{HO}+\mathrm{HO}^{-}+\mathrm{Fe}^{3+}
\end{aligned}
$$

2. The peroxynitrate pathway:

$$
\mathrm{O}_{2}^{-}+\cdot \mathrm{NO} \text { (nitric oxide) } \rightarrow \mathrm{ONOO}^{-}
$$

(peroxynitrite anion)

$$
\begin{aligned}
& \mathrm{ONOO}^{-}+\mathrm{H}^{+} \Leftrightarrow \mathrm{ONOOH} \\
& \mathrm{ONOOH} \Leftrightarrow \mathrm{HO} . \\
&+\cdot \mathrm{NO}_{2} \text { (nitrogen dioxide) } \\
& \Downarrow \\
& \mathrm{NO}^{3-} \text { (nitrate anion) }
\end{aligned}
$$

It is not clear which of these reactions predominates in the cytotoxic actions of neutrophils on endothelial cells; the evidence is conflicting. On the one hand, the presence of the iron chelator, deferoxamine, which interacts with $\mathrm{Fe}^{3+}$ in the endothelial cells, is highly protective against neutrophil-mediated cytotoxicity, ${ }^{5,14}$ and addition of iron to endothelial cells causes them to be highly susceptible to neutrophil-mediated injury. On the other hand, it has been shown that deferoxamine will react with peroxynitrite to block the formation of $\mathrm{HO} \cdot{ }^{15}$ While neutrophils generate very small amounts of $\mathrm{NO}$, macrophages stimulated with endotoxin and endothelial cells stimulated with bradykinin or 
acetyl choline produce much larger amounts of -NO. In fact, $\mathrm{NO}$ is the endothelial-derived relaxing factor, which appears to regulate vascular tone. It will be important to define the extent to which either or both of the pathways listed above contribute in vitro and in vivo to endothelial cell killing by products of activated neutrophils.

\section{IN VIVO MECHANISMS OF ACUTE VASCULAR INJURY}

\section{Lung Injury Following Systemic Activation of Complement}

Two models of acute pulmonary vascular injury in rats have been highly instructive. In one, acute vascular injury is produced by the bolus intravenous infusion of cobra venom factor (CVF), which is a highly potent activator of the alternative complement pathway, resulting in the generation of anaphylatoxins, C3a and C5a, and the membrane attack complex, C5b-9. This abrupt intravascular activation of complement results in the activation and aggregation of blood neutrophils that became entrapped within the pulmonary microvasculature, bringing about the focal damage and destruction of endothelial cells, with resulting intra-alveolar edema, fibrin deposition, and hemorrhage. ${ }^{16}$ This model may be a prototype of human adult respiratory distress syndrome and has accordingly been studied in some detail. The damage of vascular endothelial cells is neutrophil and complement dependent, since lack of access to either profoundly reduces the expression of vascular damage. Endothelial cell injury is also dependent on the formation of toxic oxygen products of the neutrophil (catalase is highly protective), with $\mathrm{HO}$ - being the ultimate tissue-damaging spccies. ${ }^{17}$ While the iron chelator, deferoxamine, is highly protective against lung injury in the CVF model of lung injury, for the reasons outlined above, the pathway from which $\mathrm{HO}$. (which appears to be the critical tissue-damaging factor) occurs cannot be clearly discerned.

While complement or neutrophil depletion is highly protective against lung injury, as is the infusion of catalase or scavengers of $\mathrm{HO}$. (dimethyl thiourea, dimethyl sulfoxide), additional new insights into the pathways leading to injury have been obtained. The treatment of rats with cromolyn (which has as one of its effects the inhibition of histamine release from mast cells and basophils) results in an $84 \%$ reduction in lung injury. In addition, the use of the two xanthine oxidase inhibitors, allopurinol and lodoxamine, has also diminished lung injury by $51 \%$ to $63 \% .{ }^{18}$ Although these observations may superficially seem disparate, they may be linked to our recent reports that histamine can interact with xanthine oxidase to cause an increase in its catalytic activity. ${ }^{19}$ Accordingly, the scheme of events (Fig 1) leading to acute vascular injury in the pulmonary microvasculature following systemic activation results in anaphylatoxin generation, with $\mathrm{C} 5 \mathrm{a}$ putatively causing histamine release and C5a causing direct activation of intravascular neutrophils. The presence of histamine may enhance the catalytic activity of xanthine oxidase within endothelial cells, while, as described above, activated neutrophils may also secrete elastase which, if it gains entry into the vascular endothelial cells, can also increase the amount of xanthine oxidase within endothelial cells. It would then appear that release of $\mathrm{H}_{2} \mathrm{O}_{2}$ from neutrophils results in the breakdown of ATP in the pulmonary vascular endothelial cells and the appearance of the substrates for xan-

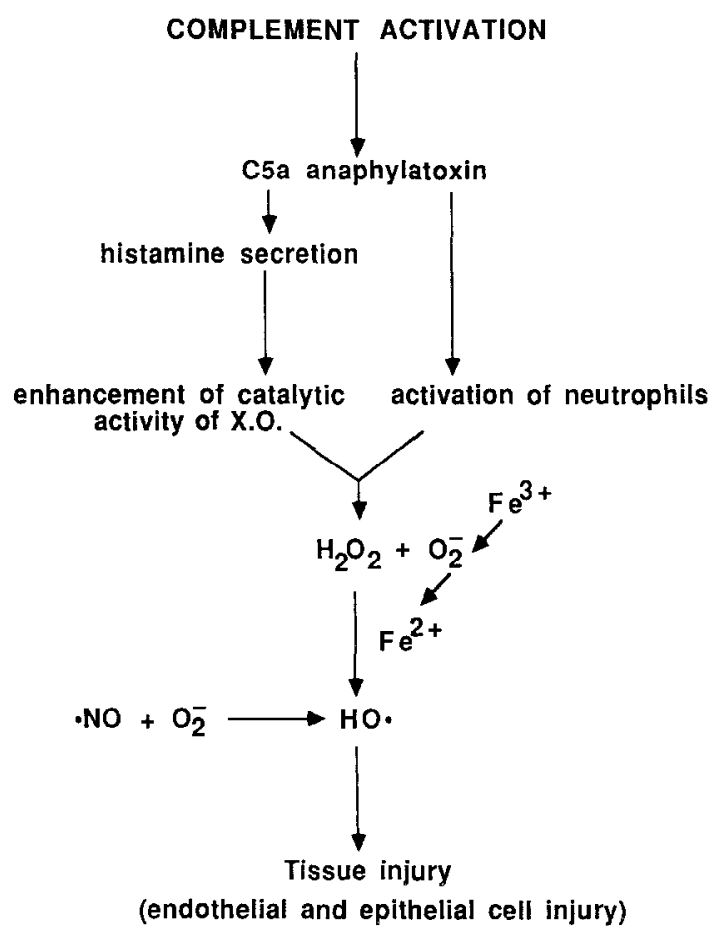

Fig 1. Acute microvascular injury in lung following intravascular activation of complement. 
thine oxidase, namely, hypoxanthine and xanthine. This production of $\mathrm{O}_{2}^{-}$by the endothelial cell may be critical to the formation of $\mathrm{HO}$, whether HO is generated by the Haber-Weiss reaction or by the peroxynitrite reaction (as described above). Because of differences in xanthine oxidase levels in endothelial cells, plasma, and tissues in various species, one must be cautious in extrapolating the scheme shown in Fig 1 to human pathophysiology. However, it does seem appropriate to consider that similar pathways may be operative in humans.

\section{Lung Injury Following Intra-alveolar Deposition of Immune Complexes}

A second model of acute lung injury has been developed in rats by the intra-alveolar deposition of immune complexes. ${ }^{20}$ Either intact, preformed immunoglobulin G-containing immune complexes can be instilled intratracheally or antibody (anti-bovine serum albumin) can be similarly instilled while antigen (bovine serum albumin) is injected intravenously. Acute hemorrhagic alveolitis ensues within a 3- to 4-hour period. This is a highly reproducible model of acute lung injury and, although the relevance of this model to human disease can be argued, the experimental model has nevertheless lent itself to a careful definition of pathophysiologic events leading to acute lung injury. This model of lung injury is, like the CVF model, dependent on the availability of both complement and neutrophils. In this model, there is an intense intraalveolar accumulation of neutrophils. There is also compelling evidence that in contrast to the CVF model of lung injury, immune complexinduced injury is not only the result of products rcleascd from activated neutrophils but also of products released from lung macrophages. The proposed outline of events is shown in Fig 2. Intra-alveolar deposition of immune complexes leads to complement activation and to activation of alveolar macrophages. ${ }^{21,22}$ The latter cells release at least three important products: oxygen derivatives $\left(\mathrm{O}_{2}^{-}\right.$and $\left.\mathrm{H}_{2} \mathrm{O}_{2}\right)$, platelet-activating factor (PAF), and cytokines (tumor necrosis factor- $\alpha$ and interleukin- $1 \beta)$. Tumor necrosis factor- $\alpha$, which is present in high concentrations in the bronchoalveolar lavage fluids of animals undergoing interpulmonary deposition of immune complexes, seems to be essential for the intraalveolar deposition of immune complexes

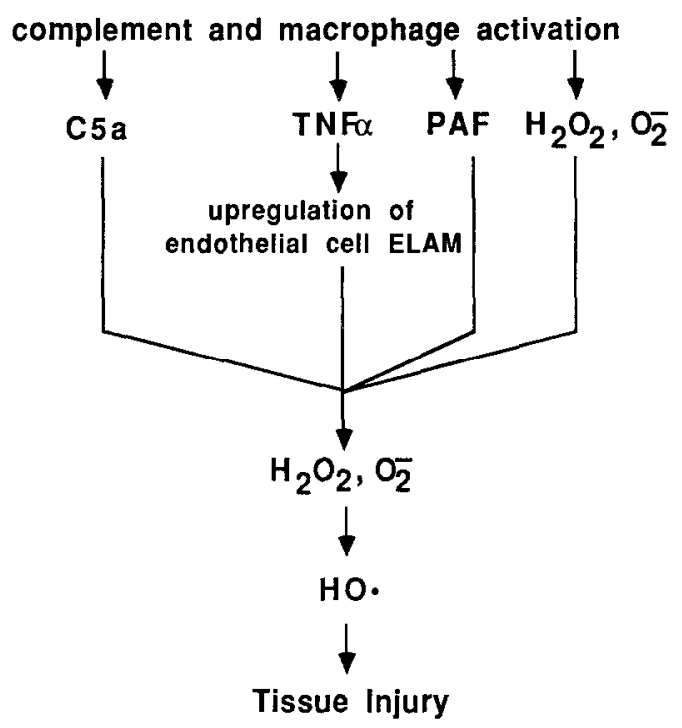

Fig 2. Acute lung injury following deposition of immunoglobulin $\mathbf{G}$ immune complexes.

recruitment of neutrophils. It seems likely that this may be due to the upregulation on endothelial cells of adhesion-promoting molecules, such as ELAM-1 (see above). Expression of ELAM-1 seems to be required for the intra-alveolar accumulation of neutrophils. The lipid factor (PAF) produced by alveolar macrophages also plays an important role in the outcome of injury, since interception of its action by the presence of antagonists of PAF receptors greatly reduced intrapulmonary injury after deposition of immune complexes. ${ }^{22}$ Platelet-activating factor receptor antagonists do not interfere with the recruitment of neutrophils. They seem to block the effects of PAF on recruited neutrophils, including "priming" these cells for enhanced responses or the direct stimulation of neutrophils. Ultimately, damage of vascular endothelia cells and alveolar epithelial cells is due to the release of the oxidants from neutrophils and, perhaps, also from macrophages. The chief oxidant incriminated in the injury is, again, $\mathrm{HO}$.

What is interesting in the comparison of these two models of acute lung injury is the evidence that in one (immune complex-induced injury), products of macrophages, including cytokines, play a prominent role, whereas in the other, cytokines do not appear to play an important 
role (eg, infusion of antibody to block tumor necrosis factor- $\alpha$ does not reduce pulmonary injury in the CVF model). The complexity of events that result in damage of endothelial cells (and other cell types) either in vitro or in vivo seems somewhat daunting, and the recognition of the diversity of pathways of injury paves the way for the consideration of a variety of therapeutic interventions that, in human inflammatory diseases, should yield beneficial clinical outcomes.

\section{REFERENCES}

1. Osborn L: Leukocytc adhesion to endothclium in inflammation. Cell 62:3-6, 1990

2. Phillips ML, Nudelman E, Gaeta FCA, et al: ELAM-1 mediates cell adhesion by recognition of a carbohydrate ligand, sialyl-Le ${ }^{x}$. Science 250:1130-1132, 1990

3. Walz G, Aruffo A, Kolanus W, et al: Recognition by ELAM-1 of the sialyl-Le ${ }^{x}$ determinant on myeloid and tumor cells. Science 250:1132-1135, 1990

4. Varani J, Bendelow MJ, Sealey DE, et al: Tumor necrosis factor enhances susceptibility of vascular endothelial cells to neutrophil-mediated killing. Lab Invest 59:292 295, 1988

5. Varani J, Fligiel SE, Till GO, et al: Pulmonary endothelial cell killing by human neutrophils. Possible involvement of hydroxyl radical. Lab Invest 53:656-663, 1985

6. Weiss SJ: Tissue destruction by neutrophils. N Engl J Med 320:365-376, 1989

7. Varani JS, Phan SH, Gibbs DF, et al: $\mathrm{H}_{2} \mathrm{O}_{2}$-mediated cytotoxicity of rat pulmonary endothelial cells: Changes in adenosine triphosphate and purine products and effects of protective interventions. Lab Invest 63:683-689, 1990

8. Hyslop PA, Hinshaw DB, Halsey WA, et al: Mechanisms of oxidantmediated cell killing: The glycolytic and mitochondrial pathways of ADP phosphorylation are major targets of $\mathrm{H}_{2} \mathrm{O}_{2}$-mediated injury. J Biol Chem 263:16651677,1988

9. Phan SH, Gannon DE, Varani J, et al: Xanthine oxidase activity in rat pulmonary artery endothelial cells and its alteration by activated neutrophils. Am J Pathol 134:1201 1211,1989

10. Granger DN: Role of xanthine oxidase and granulocytes in ischemia-reperfusion injury. Am J Physiol 255: H1269-H1275, 1988

11. Phan SH, Gannon DE, Ward PA: Mechanisms of neutrophil-induced xanthine dehydrogenase to xanthine oxidase conversion in endothelial cells. Evidence of a role for elastase. (in press)
12. Jarasch ED, Bruder G, Heid HW: Significance of xanthine oxidase in capillary endothelial cells. Acta Physiol Scand (Suppl) 548:39-46, 1986

13. Friedl HP, Smith DJ, Till GO, et al: Ischemiareperfusion in humans: Appearance of xanthine oxidase activity. Am J Pathol 136:491-495, 1990

14. Gannon DE, Varani J, Phan SH, et al: Source of iron in neutrophil-mediated killing of endothelial cells. Lab Invest 57:37-44, 1987

15. Beckman JS, Beckman TW, Chen J, et al: Apparent hydroxyl radical production by peroxynitrite: Implications for endothelial injury from nitric oxide and superoxide. Proc Natl Acad Sci USA 87:1620-1624, 1990

16. Till GO, Johnson KJ, Kunkel R, et al: Intravascular activation of complement and acute lung injury. Dependency on neutrophils and toxic oxygen metabolites. J Clin Invest 69:1126-1135, 1982

17. Ward PA, Till GO, Kunkel R, et al: Evidence for role of hydroxyl radical in complement and neutrophil-dependent tissue injury. J Clin lnvest 72:789-801, 1983

18. Till GO, Friedl HP, Ward PA: Lung injury and complement activation: Role of neutrophils and xanthine oxidase. Free Radic Biol Med (in press)

19. Friedl HP, Till GO, Trentz $O$, et al: Roles of histamine, complement and xanthine oxidase in thermal injury of skin. Am J Pathol 135:203-217, 1989

20. Ward PA, Johnson KJ, lill GU: Animal models of oxidant lung injury. Respiration 50:5-12, 1986

21. Warren IS, Yabroff KR, Remick DG, et al: Tumor necrosis factor participates in the pathogenesis of acute immune complex alveolitis in the rat. J Clin Invest 84:18731882,1989

22. Warren JS, Mandel DM, Johnson KJ, et al: Evidence for the role of platelet-activating factor in immune complex vasculitis in the rat. J Clin Invest 83:669-678, 1989 